informed that the smell of American pennyroyal (Hedeoma pulegioides), when sufficiently strong, drives them away at once. A few drops of the essential oil extracted from this plant added to an ointment and rubbed upon the skin will secure relief from these pests; likewise a sleeping apartment may be freed from them by strewing about a quantity of the leaves of the plant; or by allowing a quantity of the essential oil to evaporate in it. European pennyroyal (Mentha pulegium) is said to be very similar, and might possibly have the same effect.

Lyons, New York, August 30

M. A. VEEDER

\section{Hardening of Steel}

In NATURE, vol. xxii. p. 220, Mr. H. T. Johnston-Laris supposes the absorption of hydrogen to be necessary for steel to get hard.

The following facts seem to prove that this absorption can be very well dispensed with in hardening :-

I. Small pieces of steel wire can be hardened by moving them swiftly through the air when red hot, or by pressing them against a piece of cold metal.

2. Steel can be hardened very well by cooling in quicksilver. Both facts seem to state that only rapid cooling is wanted for steel to get hard.

Dordrecht, iSeptember 8

T. W. GiLTAY

\section{THE NEW ZEALAND INSTITUTE}

PROBABLY none of our colonies have done so much for the promotion of the higher interests of their people as New Zealand; in this respect, indeed, it will compare favourably with almost any other country in the world. Its university is wonderfully complete and well organised; all the faculties are well represented ; science, as well as literature, has its right place in the curriculum; the best men are tempted to go out as professors from the old country; and laboratory research is fairly encouraged. Quite recently we referred to a proposed system of education, which in its comprehensiveness and completeness will hold its own with any national system of education in Europe. The New Zealand Institute, again, is probably one of the best organised, and for its purpose, among the most efficient scientific bodies to be found anywhere. It is virtually a Government institution, and was organised by a special Act in 1867 . It seems to bear the same relation to its incorporated societies that a university does to its affiliated colleges; it is independent of these societies, which must comply with certain rules imposed upon them by the Institute, and yet without these societies its occupation would seem to be gone. One part of its duty is the publication of summaries of the Proceedings of the societies, and of such papers and records in full as the Institute may deem of permanent scientific value. The societies at present incorporated with the Institute are the Wellington Philosophical Society, the Auckland Institute, the Philosophical Institute of Canterbury, the Otago Institute, the Westland Institute, and the Hawkes Bay Philosophical Institute. It must be gratifying in the highest degree to those who have the best interests of New Zealand at heart to find a love for culture so widespread as the existence of these societies indicate. And it must be remembered that, as a condition of incorporation with the Institute, each society must come up to a certain standard of membership and contribute a considerable sum yearly to the promotion of science, art, and literature, which is the aim of the Institute.

The genuine good work which the Institute is doing, and its efficiency in promoting not only science, but through that the practical interests of the colony, is evident from the handsome volume of Transactions which it publishes yearly, and which are entitled to take their place among the best class of similar publications. Some idea of the work which the Institute is doing, and of the value of its Transactions, may be obtained from the two last volumes, for 1878 and 1879 , which we have just received.

Of course the first aim of a society like this, in a fresh country like New Zealand, should be the working ont of its natural history (in its widest sense) in a scientific method. This the Institute has done and is doing, and its publications, and the publications of the separate societies, are already a mine of information on all subjects connected with New Zealand. The volumes before us contain a large number of papers on zoology, botany, chemistry, and geology, all of them important contributions to these various departments of science. Prof. Hutton, whose name is well known in this country, contributes a number of valuable papers on the various divisions of the fauna of New Zealand. Prof. von Haast (another name well known to science) has other various contributions of special value, and Mr. T. W. Kirk, of the Colonial Museum, has a long list of papers both on zoology and botany, all of them of novelty and interest, and several of them on such practically important subjects as Grasses and Fodder Plants. Other able workers in these departments are Mr. $D$. Petrie, Mr. W. Colenso, Mr. Charles Knight, Mr. Buchanan, and Mr. Buller. From Mr. J. C. Craufurd and Mr. W. Collie we have valuable contributions relating to the geology of New Zealand. Several of the papers classed under the head of Miscellaneous are of the greatest importance and interest. Thus we have papers of immense practical value to the colony on the Forest Question in New Zealand, by Mr. A. Lecoy; on the Influence of Forests on Climate and Rainfall, by Mr. F. S. Peppercorne; and on Forest Planting and Conservation, by Mr. G. W. Wilkins. Equally important from a colonial as well as a scientific standpoint is Commander Edwin's paper on the Principle of New Zealand Weather Forecast. We have several excellent papers on the New Zealand natives of much ethnological value : "Notes on Port Nicholson and the Natives in 1839," by Major Heaphy; "On the Ignorance of the Ancient New Zealander of the Use of Projectile Weapons," by Mr. Coleman Phillips; "Contributions towards a Better Knowledge of the Maori Race," by Mr. W. Colenso; "Notes on an Ancient Manufactory of Stone Implements," by Prof. von Haast, F.R.S. ; and "Notes on the Colour-Sense of the Maori," by Mr. J. W. Stack. Mr. W. Colenso contributes papers on the Moa, a subject of great scientific interest. Mr. J. H. Pope's "Notes on the Southern Stars and other Celestial Objects" is a valuable contribution to astronomy. Prof. Bickerton has several papers on subjects of wide scientific interest,-on "Partial Impact," the "Genesis of Worlds and Systems," the "Birth of Nebulæ" ; while Prof. F. W. Frankland writes interestingly on "The Doctrine of Mind-Stuff." There are several good chemical papers by Mr. W. Skey. In the Proceedings of the several societies there are numerous shorter papers of varied interest, as on Moa Feathers, by Dr. Hector ; on Musical Tones in the Notes of Australian Birds, by Mr. C. W. Adams; on a new fish, by Prof. Hutton; and many others on subjects of wide and varied interest. We have besides meteorological, earthquake, and other records, and a variety of miscellaneous matter, all of real importance.

An institution capable of producing so much valuable work year after year deserves every encouragement from the government of the country. The New Zealand Government has hitherto granted a subsidy of $500 \%$. yearly to the Institute, just sufficient, we believe, to defray the expenses of printing the Transactions, which are freely distributed to other societies all over the world. We are therefore astounded to learn that the Government has decided to withdraw this grant, thus suddenly bringing these valuable Transactions to a standstill. We can scarcely credit the statement; it is difficult to believe that so enlightened a Government as that of New Zealand 
would so seriously cripple one of its most valuable institutions, and so discourage an activity which produces results not only of the greatest value to science, but to the practical interests of the colony. The affiliated societies themselves contribute, we bclieve, $\mathrm{r}, 275 \%$. annually to support the work of the Institute, the whole of which is spent in keeping up valuable museums and laboratories, and an interest in science in ninc centres of population in New Zealand. Without the annual volume, we fear it is impossible to get members to keep up their subscriptions, and thus the organisation of the Institute, which has stood the test of twelve years, given universal satisfaction at home and abroad, and reflected the greatest credit on the colony, is in danger of breaking up and possibly expiring altogether. This would be little less than a calamity to the colony. Not a penny of the 500 . is spent in salaries ; the editing, drawing of illustrations, and all else is a mere labour of love. The names of von Haast, Hector, Hutton, and others, are known to men of science all over the world. Dr. Hector especially has acquired a high reputation for his activity, zeal, and the results he has obtained. It is greatly owing to him that New Zealand has done for science far more than any colony of its age. The Institute itself is a model of organisation. The grant of the annual 50ol. was a wise step worthy of general imitation, and its sudden extinction is a cruel blow to science. We can scarcely believe that New Zealand is capable of persisting in carrying out so shabby and short-sighted a policy, a policy of which any country should be ashamed. We trust that later news will show that there has been some misunderstanding, or that the Government has thought better of it, and continued a grant that could not possibly be better spent.

\section{ALBERT 7. MYER}

$\mathrm{T}$ $\mathrm{HE}$ young science of meteorology has sustained another heavy loss in the death of General Myer, of the Signal Service of the United States, at Buffalo, New York, on August 24, in the fifty-second year of his age. In 1854 he entered the United States army as an assistant surgeon, was assigned to special duty in the Signal Service in 1858 , and in 1860 was made chief signal officer of the army, a position he held till his death.

The distinguished services rendered by General Myer to meteorology may be considered as having been made chiefly during the last ten years. Americans claim for the late Prof. Henry, of the Smithsonian Institution, the honour of having originated, upwards of thirty years ago, the idea of using the telegraph for conveying information regarding coming changes of weather. But it was rescrved to General Myer, as respects the United States, to translate the idea into the action of every-day life, in devising, developing, and extending a system of telegrams and reports for the benefit of commerce and agriculture, which as regards the completeness of its organisation, the thoroughness with which it is worked, and its effective success, stands out as a model system of weather telegraphy, Three large weather maps are prepared and issued daily, along with three daily forecasts of the weather, which the telegraph at once sends through all the towns, villages, and hamlets of the States; and no time is lost, on the expiry of each month, in preparing and widely circulating a Weather Review, accompanied with maps showing the storm tracks, the geographical distribution of the atmospheric pressure, temperature and rainfall for the month; together with occasional weather-maps of the highest importance in their bearing on the meteorology of America, Europe, and the rest of the northern hemisphere.

The other grcat service rendered by General Myer to practical science is the system of international meteorology established by him, one of the important outcomes of which is the series of United States weather-maps now appearing in NATURE, showing the meteorology of the globe for each month. When the scheme was first proposed to the Meteorological Congress at Vienna, in 1873, it was difficult to regard it in any other light than as an impracticable, if not wholly visionary, proposal; but the feeling quickly changed as General Myer unfolded the details of its practical working, and explained that what he required from his brother meteorologists, in addition to their approval of the scheme, was one daily observation at a selected few of their stations, he being authorised by the American Government to say that they would undertake the expense of collecting and discussing the observations.

As our readers are aware, the scheme in General Myer's hands has been a pre-eminent success; and a body of facts is being thercby amassed, destined to furnish the key to the larger problems of meteorology, a science which, from the complex intricacies it presents, requires more than any other science a whole hemisphere at least as its basis of observation. Perhaps the most important of the practical questions which will thus fall to be dealt with are those abnormal distributions of the mass of the earth's atmosphere, short continued or more permanent, from which arise great storms or devastating tornadoes, excessive heat or cold, fine seasons or their opposites, and long-continued rains or droughts, so terrible for the famines which attend them. The explanation of these anomalies will doubtless be the immediate precursor of an intelligent and practically successful forecasting of the character of coming seasons.

This magnificent work General Myer could not have accomplished unless he had been backed by the moral and material assistance so generously and readily accorded him by his Government. With a settled conviction that this national work, if undertaken at all, should be carried out in a spirit and manner worthy of the great Republic, the Government of the United States relegated the work to the Signal Service of the War Department, with an annual vote from the Exchequer, which, while not too large for the work to be done, no.Government on this side the Atlantic has yet thought of emulating.

While writing this brief notice of General Myer's work, we have been repeatedly reminded of the name of Leverrier-probably because, though widely different in many ways, both rendered services to meteorology to a great extent identical, both possessed the rare genius of organising and the resolute will that easily sets obstacles aside, both secured the support of their respective Governments, both were animated by large views of the capabilities and requirements of the science, and both were successful in an eminent degree in largely extending the sphere of its operations.

\section{PHYSICS WITHOUT APPARATUS ${ }^{1}$}

$\mathrm{V}$.

THE Scicnce of Electricity may be regarded in several different aspects. Firstly, there is the study of the simple phenomena such as schoolboys delight to see: the attractions and repulsions of rubbed bodies, the sparks, the shocks, the heating of wires, and rotation of diminutive electric engines. Secondly, there is the exact measurement of electrical quantities, and the verifying of the great laws of the science, involving exact manipulation and standard instruments. Thirdly, there is the technical study of the applications of the science, the details of telegraphic apparatus, the necessities of construction and maintenance, the management of electric lights, and other branches of electrical engineering. Lastly, comes the high mathematical theory cultivated only by the few.

Of the practical portions of this vast mine of scientific wealth, the greater part is only to be reached by the aid

\footnotetext{
${ }^{x}$ Continued from p. 440.
} 